\title{
GENETIC ANALYSIS OF FEET AND LEG CONFORMATION AND PROPORTION OF CRUSHED PIGLETS IN AUSTRIAN LARGE WHITE AND LANDRACE SOWS
}

\author{
Christina Pfeiffer ${ }^{1}$, Birgit Fuerst-Waltl ${ }^{1}$, Katharina Schodl ${ }^{1}$, Peter Knapp ${ }^{2}$ \\ ${ }^{1}$ Division of Livestock Science, Department of Sustainable Agricultural Systems, University of Natural Resources \\ and Life Sciences (BOKU), Gregor-Mendel Strasse 33, 1180 Vienna, Austria \\ ${ }^{2}$ Schweinezuchtverband \& Besamung OOE, Waldstraße 4, 4641 Steinhaus, Austria
}

To link to this article: https://doi.org/10.11118/actaun201967051213

Received: 19. 7. 2019, Accepted: 26. 8. 2019

To cite this article: PFEIFFER CHRISTINA, FUERST-WALTL BIRGIT, SCHODL KATHARINA, KNAPP PETER. 2019. Genetic Analysis of Feet and Leg Conformation and Proportion of Crushed Piglets in Austrian Large White and Landrace Sows. Acta Universitatis Agriculturae et Silviculturae Mendelianae Brunensis, 67(5): 1213-1219.

\begin{abstract}
Selection for feet and leg traits can increase longevity as well as several performance traits in sows. Moreover, good feet and leg quality contributes improving animal welfare not only for sows, but also for piglets. Sows with feet and leg problems have a higher risk of crushing their piglets when lying down. Therefore, a feet and leg scoring scheme was derived and applied by trained assessors. Furthermore, piglet mortality rate by crushing was recorded. Genetic parameters as well as breeding values were estimated and the effect of the traits on piglet mortality rate by crushing was investigated. Data of 993 Large White and 299 Landrace sows of 23 nucleus farms were analyzed. Heritabilities ranged from 0.03 to 0.16 for piglet mortality rate by crushing and pastern fore legs. Some genetic correlations between feet and leg traits were significantly highly correlated (0.69 to 0.79). Sows with favorable scores for almost all feet and leg scores had higher estimated breeding values for piglet mortality rate. Higher values indicate less crushed piglets and are thus favorable. An introduction of a feet and leg scoring scheme into routine genetic evaluation may thus contribute to animal welfare improvement for sows and piglets.
\end{abstract}

Keywords: pigs, genetic parameters, feet and leg conformation, crushed piglets, animal welfare

\section{INTRODUCTION}

Besides economic losses, weak feet and legs present a serious welfare issue in various livestock species. They can lead to abnormal locomotion behavior as well as lameness. Animals experience distress and pain, which may reduce performance and finally lead to early culling (e.g. Hellbrügge, 2007; Köck et al., 2019). The culling rate in productive sows due to lameness ranges from 10 to 20\% (Anil et al., 2009). Anil et al. (2009) found that there were fewer live born piglets in litters from lame sows compared to sows showing no signs of lameness. Le et al. (2015) estimated genetic correlations between eight feet, leg and toe traits and production traits of first and second parity purebred Yorkshire sows. The authors found positive genetic correlations between the number of live born piglets and sows with better feet, leg and toe scores $\left(r_{a}=0.20\right.$ to 0.36). Furthermore, piglets of sows with weak feet and legs or lame sows may have a higher risk of being crushed by their mother. Sows with weak extremities, particularly of the hindquarters, are not able to lie down in a controlled and slow manner, which leads to a higher risk for injured and crushed piglets, especially in narrow farrowing pens or farrowing pens with crates (Damm et al., 
2005; Pluym et al., 2013). Reasons for weak feet and legs, abnormal locomotion behavior and lameness can be manifold. Poor housing conditions, unbalanced nutritional diets as well as genetic factors often cause weak feet and legs along with the consequences mentioned above (Luther et al., 2007; Heinonen et al., 2013). Furthermore, osteochondrosis lesions have an impact on feet and leg quality. Several authors estimated genetic parameters for osteochondrosis and feet and leg traits and found them to be moderately heritable and genetically correlated (Koning et al., 2012; Luther et al., 2007; Jørgensen and Andersen, 2000). Therefore, Koning et al. (2012) proposed to use several characteristics of feet and leg traits for selection. In Austria, boars and gilts are currently selected based on phenotypic overall characteristics by the official breeding organizations. However, no breeding values for feet and leg traits are available at time of selection when pigs are on average six months old. Additionally, Austrian animal welfare legislation currently allows sows to be crated for ten days during the insemination period, for five days before birth and during the whole suckling period. New legislation demands that as of 2033, sows are only allowed to be in farrowing pens five days before the expected farrowing date and can be crated until the critical phase for survival of the piglets is over (BMFG Austria, 2019). In the light of these developments, Austrian pig breeding organizations established a feet and leg scoring scheme as part of a more animal welfare friendly pig breeding program. The aims of this study were the application of a feet and leg scoring scheme in the Austrian nucleus population of Large White and Landrace sows, the estimation of genetic parameters for six derived feet and leg traits and to investigate how these traits affect piglet mortality rate by crushing during suckling period.

\section{MATERIALS AND METHODS}

The assessment was carried out on 23 nucleus farms in the three main pig producing counties in Austria (Styria, Lower, and Upper Austria) between October 2017 and July 2018. The 23 nucleus farms participated in a larger project, which was launched by the pig breeding organizations and BOKU University. Altogether, 1,309 Large White, Landrace and F1 sows were assessed for this study. All sows on the breeding units were kept in compliance with Austrian animal welfare legislation (BMFG Austria, 2019).

\section{Feet and Leg Scoring}

A scoring scheme comprising six traits was established based on already existing feet and legs scoring schemes (Brandt and Henne, 2004; Fernández et al., 2005; Hellbrügge, 2007; Tab. I).

This feet and leg scoring scheme has not been applied on Austrian pig breeding farms before. Five employees of the breeding organizations were assigned to perform the assessment and were trained in one training session comprising a theoretical and a practical part. For the practical part, they had to asses 30 sows in different stages of production (gilt, waiting area, farrowing pen) using the above described feet and leg scoring scheme. These 30 sows were tagged with numbers and had been selected and assessed by the trainer from BOKU University beforehand. The scores of the trainer served as gold standard. To assess the agreement of the five employees with the gold standard, bias-adjusted kappa coefficients (Byrt et al., 1993) or percentage of agreement (for claws and lameness) were calculated. Employees had to obtain a kappa value or agreement, respectively, of at least 0.60 for each trait, otherwise employees were retrained. Routine data collection was carried out using an adopted application of the routine data collection software package 'Sauenplaner' (Intelicon, 2019). Each breeding unit was visited once during the data collection period. During this visit, one of the five employees scored the entire productive stock.

\section{Piglet Mortality by Crushing}

Austrian pig breeders collected fertility traits as well as piglet mortality routinely using the software package 'Sauenplaner' (Intelicon, 2019). In the course of this project, breeders were trained twice to assess the cause of death. A detailed description of training and recording of piglet mortality can be found in Schodl et al. (2019). For the present

I: Feet and leg scoring scheme for Large White and Landrace sows

\begin{tabular}{lclcc}
\hline \multicolumn{1}{c}{ Trait } & Abbreviations & Definition of the trait & Range & Optimum \\
\hline Side view fore legs & SV_FL & Extremely buckled to extremely sickled & -2 to 2 & 0 \\
Pastern fore legs & P_FL & Extremely high to extremely weak & -2 to 2 & 0 \\
Side view hind legs & SV_HL & Extremely steep to extremely standing under & -2 to 2 \\
Pastern hind legs & P_HL & Extremely high to extremely weak & -2 to 2 \\
Claws & CL & $\begin{array}{l}\text { Equally long, one side is slightly longer, one or both } \\
\text { sides are too long }\end{array}$ & $0,1,2$ \\
Lameness & LA & Not lame, lame & 0 & 0 \\
\hline
\end{tabular}


study, only the number of piglets which died by crushing of the sow were extracted and divided by the number of live born piglets to obtain piglet mortality rate by crushing. Two traits were defined for further genetic analyses. The first trait was defined as the piglet mortality rate by crushing within the first two days postpartum (CP_2D) and the second trait was defined as the piglet mortality rate by crushing until the end of the suckling period (CP_35D). Litters with suckling periods longer than 35 days were discarded. Data of fertility traits and piglet mortality were recorded for the period of one year. Several sows farrowed more than once during this period and thus more than one observation for the traits CP_2D and CP_35D was available for these sows.

\section{Statistical Analysis}

Data of leg scoring sows and piglet mortality were merged for Large White and Landrace, resulting in a final data set of 993 Large White and 299 Landrace sows from 20 farms. For CP_2D and CP_35D 1,672 records were available. Additionally, farrowing classes were derived based on the farrowing age of the sow (in months), resulting in eight different farrowing classes. Six farrowing seasons were defined to account for the month of farrowing, summarizing two consecutive months. All sows with parity equal to or higher than ten were summed up in one parity class, yielding ten parity classes. The five employees of the breeding organizations scored the sows over a period of almost a year. Therefore, classes for the time of scoring were created by combining two months, resulting in six scoring time classes. Furthermore, 15 classes were defined to correct for pregnancy stage. The pedigree was traced back as far as possible, yielding 13,961 animals. For all models, preliminary least squares analyses using the PROC MIXED of SAS version 9.4 (SAS Institute Inc., 2013) were used to select significant fixed effects to be included in the genetic analyses. Subsequently, random effects were added and analyses were conducted applying an average information algorithm using ASReml 3.0 (Gilmour et al., 2009). Heritabilities and breeding values were estimated fitting a univariate linear animal model. Genetic and phenotypic correlations for feet and leg traits were calculated fitting a bivariate linear animal model. The following models were fitted for feet and leg traits (Model 1) and for piglet mortality by crushing (Model 2).

\section{Model 1:}

$$
\begin{aligned}
\mathrm{y}_{\mathrm{fl}}= & \text { employee }(\text { farm })+\text { farm }+ \text { breed }+ \\
& + \text { farrowing class* parity }+ \text { scoring time }+ \\
& + \text { pregnancy stage }+\mathrm{a}+\mathrm{e} .
\end{aligned}
$$

\section{Model 2:}

$$
\begin{array}{r}
y_{c p}=\text { farm + breed + farrowing class*parity }+ \\
+ \text { farrowing season }+b^{*} \text { npig }+a+p+e,
\end{array}
$$

where $\mathrm{y}_{\mathrm{fl}}$ and $\mathrm{y}_{\mathrm{cp}}$ are the phenotypic observations for feet and leg traits and piglet mortality by crushing, respectively; employee is the fixed effect for the employee of the breeding organizations. One employee visited different farms and thus the fixed effect farm was nested in the fixed effect employee. Breed accounts for the fixed effect of the sow breed Large White or Landrace. Further fixed effects were farrowing class, parity, scoring time, season of farrowing and pregnancy stage. Furthermore, a represents the random additive genetic effect of the sow, $\mathrm{p}$ is the permanent environmental effect of the sow and e represents the residual effect. To account for litter size, the total number of born piglets was fitted as a covariate in the second model (npig). Breeding values for all traits were calculated as relative estimated breeding values (EBVs) on a rolling base with a mean of 100 and 20 points for one genetic standard deviation where higher values are desirable. For CP_2D and CP_35D breeding values were multiplied with -1 because higher EBVs are favorable, indicating less crushed piglets and a lower proportion of crushed piglets should result in higher EBVs.

Due to the intermediate optimum of zero, a straightforward estimation of genetic and phenotypic correlations between feet and leg traits and crushed piglets was not performed in this study. Nevertheless, a simple ANOVA was conducted using PROC GLM of SAS version 9.4 (SAS Institute Inc., 2013) fitting the following model:

$\mathrm{y}_{\mathrm{EBV}}=$ score $+\mathrm{e}$,

where $\mathrm{y}_{\mathrm{EBV}}$ represents the estimated breeding values of CP_2D and CP_35D, score is the fixed effect of the score of all six feet and leg traits and e represents the residual effect. Tukey-Kramer was applied to test for significant differences between feet and leg traits.

\section{RESULTS}

The bias-adjusted kappa coefficients for the employees ranged from 0.23 to 0.70 and differed between traits. High bias-adjusted kappa coefficients were achieved for front and hind pastern whereas kappa coefficients for side view of the front and hind legs were comparatively low. The percentage of agreement for lameness and claws ranged from 0.83 to 0.90 . One employee was retrained and was able to achieve sufficient values afterwards. The distributions of the six feet and legs scores were narrow. For the traits side view fore legs $87.2 \%$, pastern fore legs $67.6 \%$, side view hind legs $70.6 \%$ and pastern hind legs $54.9 \%$ of the sows were scored 0 , which reflects the intermediate 
optimum. On average, the means of the six feet and leg traits were close to zero. Regarding lameness, $96.5 \%$ of the sows were scored 0 (not lame) and $85.0 \%$ of the sows had equally long claws (score of 0 ). The descriptive statistics, heritabilities as well as EBVs of all traits are presented in Tab. II. The percentage of crushed piglets almost doubled from day 1 to the end of the suckling period. Both, heritabilities and piglet mortality rate by crushing until day 2 and until the end of the suckling period were low. Heritabilities for feet and leg traits ranged from 0.03 for lameness to 0.16 for pastern fore legs. Standard errors were rather high and heritabilities were not significantly different from zero for the traits side view fore legs, claws, lameness and piglet mortality rate by crushing until day 2. EBVs were around the mean of 100 . Tab. III presents genetic correlations of the six feet and legs traits. Almost all genetic correlations between feet and leg traits were moderate to high, but almost half of them were not significantly different from zero. A strong and significant genetic correlation was found between side view fore legs and pastern fore legs $\left(r_{a}=0.77\right)$, pastern fore legs and pastern hind legs $\left(r_{a}=0.77\right)$, pastern fore legs and pastern hind legs $\left(r_{a}=0.67\right)$, side view hind legs and pastern hind legs $\left(r_{a}=0.71\right)$ and pastern hind legs and claw length $\left(r_{a}=0.79\right)$, respectively. This means, that for example sows with weak fore leg pasterns also showed weak hind leg pasterns.

Due to the fact that extreme scores $(-2,2$, respectively) were rarely scored, they were subsumed under one score (-1, 1, respectively) to conduct the simple ANOVA. No significant differences for EBVs for piglet mortality rate by crushing until day 2 were found between feet and legs scores and thus results are not presented. Tab. IV presents the Least squares means (LSmeans) for the EBVs for piglet mortality rate by crushing until day 35 for the six phenotypic feet

II: Descriptive statistics of feet and leg traits, piglet mortality rate by crushing and corresponding heritability estimates as well as their standard errors. Heritabilities in bold are significantly different from zero.

\begin{tabular}{|c|c|c|c|c|c|}
\hline Trait & $\begin{array}{c}\text { Means } \pm \text { SD } \\
\text { Feet and leg } \\
\text { score/percentage } \\
\text { crushed piglets [\%] }\end{array}$ & $\begin{array}{c}\text { Minimum to } \\
\text { Maximum Feet and } \\
\text { leg score/percentage } \\
\text { crushed piglets [\%] }\end{array}$ & $\mathrm{h}^{2} \pm \mathrm{SE}$ & $\begin{array}{c}\text { Mean EBV } \pm S D \\
\text { Feet and leg } \\
\text { score/percentage } \\
\text { crushed piglets [\%] }\end{array}$ & $\begin{array}{c}\text { Minimum to } \\
\text { Maximum Feet and } \\
\text { leg score/percentage } \\
\text { crushed piglets [\%] }\end{array}$ \\
\hline Side view fore legs & $0.05 \pm 0.36$ & -1 to 2 & $0.09 \pm 0.05$ & $98.1 \pm 7.6$ & 67.7 to 138.6 \\
\hline Pastern fore legs & $0.33 \pm 0.54$ & -1 to 2 & $0.16 \pm 0.05$ & $97.9 \pm 9.2$ & 69.1 to 135.6 \\
\hline Side view hind legs & $0.09 \pm 0.55$ & -2 to 2 & $0.13 \pm 0.06$ & $99.8 \pm 8.6$ & 68.7 to 129.2 \\
\hline Pastern hind legs & $0.47 \pm 0.57$ & -1 to 2 & $0.13 \pm 0.05$ & $98.2 \pm 8.8$ & 73.3 to 128.6 \\
\hline Claws & $0.16 \pm 0.40$ & 0 to 1 & $0.07 \pm 0.05$ & $99.5 \pm 6.8$ & 60.0 to 116.4 \\
\hline Lameness & $0.03 \pm 0.17$ & 0 to 1 & $0.03 \pm 0.04$ & $100 \pm 4.7$ & 71.3 to 110.8 \\
\hline $\begin{array}{l}\text { Piglet mortality rate } \\
\text { by crushing until } \\
\text { day } 2\end{array}$ & $1.78 \pm 0.48$ & 5.00 to 40.0 & $0.03 \pm 0.02$ & $101.8 \pm 6.2$ & 74.0 to 125.0 \\
\hline $\begin{array}{l}\text { Piglet mortality rate } \\
\text { by crushing until } \\
\text { weaning }\end{array}$ & $3.99 \pm 7.60$ & 5.00 to 40.0 & $0.04 \pm 0.02$ & $105.2 \pm 19.5$ & 35.0 to 170.0 \\
\hline
\end{tabular}

III: Estimated genetic correlations for the six feet and leg traits side view fore legs (SV_FL), pastern fore legs (P_FL), side view hind legs (SV_HL), pastern hind legs (P_HL), claw length (CL) and lameness (LA). Genetic and phenotypic correlations in bold are significantly different from zero.

\begin{tabular}{|c|c|c|c|c|c|c|}
\hline & SV_FL & P_FL & SV_HL & P_HL & CL & LA \\
\hline SV_FL & & $\begin{array}{r}\mathbf{0 . 7 7} \\
\pm 0.24\end{array}$ & $\begin{array}{r}-0.28 \\
\pm 0.34\end{array}$ & $\begin{array}{r}\mathbf{0 . 7 0} \\
\pm 0.34\end{array}$ & $\begin{array}{r}0.50 \\
\pm 0.44\end{array}$ & $\begin{array}{r}0.85 \\
\pm 0.82\end{array}$ \\
\hline P_FL & & & $\begin{array}{r}-0.11 \\
\pm 0.30\end{array}$ & $\begin{array}{r}\mathbf{0 . 6 7} \\
\pm 0.23\end{array}$ & $\begin{array}{r}0.20 \\
\pm 0.38\end{array}$ & $\begin{array}{r}0.72 \\
\pm 0.57\end{array}$ \\
\hline SV_HL & & & & $\begin{array}{r}\mathbf{0 . 7 1} \\
\pm 0.24\end{array}$ & $\begin{array}{r}0.72 \\
\pm 0.57\end{array}$ & $\begin{array}{r}0.35 \\
\pm 0.69\end{array}$ \\
\hline P_HL & & & & & $\begin{array}{r}\mathbf{0 . 7 9} \\
\pm 0.34\end{array}$ & $\begin{array}{r}0.52 \\
\pm 0.49\end{array}$ \\
\hline CL & & & & & & $\begin{array}{r}0.74 \\
\pm 0.53\end{array}$ \\
\hline
\end{tabular}


IV: Least-squares-means (LS-means) for estimated breeding values for crushed piglets until day 35 for the six feet and leg traits side view fore legs $\left(S V_{-} F L\right)$, pastern fore legs (P_FL), side view hind legs $\left(S V_{-} H L\right)$, pastern hind legs (P_HL), claw length (CL) and lameness (LA)

\begin{tabular}{ccccccc}
\hline & SV_FL & P_FL & SV_HL & P_HL & CL & LA \\
\hline & LS-means & LS-means & LS-means & LS-means & LS-means & LS-means \\
Score & 102.6 & 96.5 & 109.9 & 104.6 & - & - \\
-1 & $105.9^{\mathrm{a}}$ & $106.4^{\mathrm{a}}$ & 106.1 & 104.7 & 105.4 & $105.5^{\mathrm{a}}$ \\
0 & $99.7^{\mathrm{b}}$ & $103.1^{\mathrm{b}}$ & 104.2 & 107.5 & 105.2 & $98.0^{\mathrm{b}}$ \\
\hline
\end{tabular}

$\mathrm{a}, \mathrm{b}$ indicate a significant difference between scores $(\mathrm{p}<0.05)$

and leg traits. LS-means for EBVs for CP_35D for the traits SV_FL, P_FL and LA showed some significant differences between scores ( $\mathrm{p}$-values ranged from 0.011 to 0.023$)$.

\section{DISCUSSION}

Training for the employees of the breeding organizations was important. Biased-adjusted kappa values showed a relatively high variation. However, a high quality phenotypic measurement is crucial for producing reliable estimates and therefore assessors should be trained regularly to avoid assessment bias. Brennikmeyer et al. (2007) showed that agreement of assessment increased significantly with the number of training sessions. Heritabilities for feet and legs were low to moderate (0.03 to 0.16) and similar to previous studies, although slightly different definition of the traits and scoring schemes were applied (e.g. Brandt et al., 2004; Le et al., 2015; Luther et al., 2007). The used data sets were fairly small, nevertheless feet and leg traits may respond to selection when traits will be included into the breeding program in future. Also the low heritabilities for piglet mortality rate by crushing were similar to other studies (e.g. Grandinson et al., 2010). A larger number of records as well as repeated measurements of sows may yield higher heritabilities. However, not all nucleus sows in Austria have been scored for feet and leg traits yet and thus piglet mortality rate by crushing was only considered for sows with feet and leg scores. A higher heritability $(0.07 \pm 0.03)$ for the trait CP_35D was found when using a larger data set of the Austrian nucleus population (2,900 records). Furthermore, piglet mortality rate by crushing may also be used as one among other traits describing good maternal behavior. Between feet and leg traits, only few high and significant genetic correlations (0.67 to 0.79) were observed. Weak pastern seemed to be highly correlated with overgrown claws.
This finding was also reported by Jørgenson and Andersen (2000). Sows with overgrown claws have a higher risk to get stuck in the slats of slatted floors which may lead to lesions and subsequent infections. In particular intensive conditions in pig farming, e.g. slatted floors and no bedding, restricted possibility to move around would therefore require good claw conditions to prevent further clinical problems. Selection for a good quality of feet and legs may not only increase performance and welfare of the sows, it may also reduce time needed for certain management practices, for example claw trimming. Sows that were scored with the optimum of zero for the traits SV_FL, P_FL, P_HL and CL as well as LA had higher or significantly higher EBVs for CP_35D, which is favorable (higher EBVs indicate less crushed piglets). Regarding the traits SV_HL and P_HL this finding could not be confirmed. Until now, a routine scoring of feet and legs is not done in the Austrian breeding program for the maternal lines Large White and Landrace. Based on the findings of the present study and further scientific literature an introduction of the above mentioned feet and leg traits into routine performance testing is recommended. Besides, Le et al. (2015) showed that longevity was improved in sows with good feet and legs ( $\mathrm{ra}=0.24$ to 0.88 ). In Austria's routine genetic evaluation for dairy cattle, several conformation traits are used as auxiliary traits for functional longevity because strong genetic correlations exist (Pfeiffer et al., 2014). If a routine genetic evaluation is implemented and these traits are considered in the breeding goal, a positive genetic trend may be possible. In compliance with good management, animal welfare, performance and longevity as well as farm economics may be improved. Nevertheless, further research regarding the relationship between performance traits and functional longevity is required for the Austrian pig population. However, a larger number of records is needed for these analyses.

\section{CONCLUSION}

Results of the study showed that feet and leg traits as well as piglet mortality rate by crushing have a genetic background and feet and leg traits are genetically correlated. Nevertheless, more data are needed to gain higher variation for phenotypic scores. Although scores for feet and leg traits were corrected for assessors in the genetic model, regular training sessions should be conducted 
to guarantee high quality phenotypic data. Good Feet and leg quality may also serve as an early indicator for sows with increased longevity and lower percentage of crushed piglets during their productive period. Routine feet and leg scoring may easily be implemented in the selection process and carried out by employees of the breeding organizations together with back fat measuring and weighing of gilts.

\section{Acknowledgements}

Authors gratefully acknowledge pig farmers for data collection as well as the employees from the breeding organizations for supporting farmers during the data collection period as well as assessing all sows. Many thanks to Christine Leeb from BOKU University for supporting the training workshop for the breeding organizations' employees

\section{Funding}

This research was funded by the Ministry of Sustainability and Tourism Austria and the Austrian Pig Farmers Association (pig.at).

\section{REFERENCES}

ANIL, S. S., ANIL, L. and DEEN, J. 2009. Effect of lameness on sow longevity. Journal of the American Veterinary Medical Association, 235(6): 734-738.

BMFG AUSTRIA. 2019. Verordnung der Bundesministerin für Gesundheit und Frauen über die Mindestanforderungenfürdie HaltungvonPferdenundPferdeartigen, Schweinen, Rindern, Schafen, Ziegen, Schalenwild, Lamas, Kaninchen, Hausgeflügel, Straußen und Nutzfischen (1. Tierhaltungsverordnung). BGBI. II Nr. 485/2004, in the version dated 3 June 2019. Available at: https://www.ris.bka.gv.at/ GeltendeFassung.wxe?Abfrage=Bundesnormen\&Gesetzesnummer=20003820 [Accessed: 2019, June 28].

BRANDT, H. and HENNE, H. 2004. Genetic correlation between exterior traits and stayability in pigs. In: 55th Annual meeting of the European Association for Animal Production (EAAP). September 5-9, Bled, Slovenia.

BRENNINKMEYER, C., DIPPL, S., MARCH, S., BRINKMANN, J., WINCKLER, C. and KNIERIM U. 2007. Reliability of subjective lameness scoring system for dairy cows. Animal Welfare, 16: 127-129.

BYRT, T., BISHOP, J. and CARLIN, J. B. 1993. Bias, prevalence and kappa. Journal of Clinical Epidemiology, 46(5): 423-429.

DAMM, B. I., FORKMAN, B. and PEDERSEN, L. J. 2005. Lying down and rolling behaviour in sows in relation to piglet crushing. Applied Animal Behaviour Science, 90: 3-20.

FERNÁNDEZ, X., PIEDRAFITA, J., TIBAU, J. and FÁBREGA, E. 2005. Development of a protocol to record functional traits and inhered disorders affecting welfare in pigs. In: $56^{\text {th }}$ Annual meeting of the European Association for Animal Production (EAAP). June 5-8, 2004, Uppsala, Sweden. Abstract No 262.

GILMOUR, A. R., GOGEL, B. J., CULLIS, B. R. and THOMPSON, R. 2009. ASReml User Guide Release 3.0. Hemel Hemstead, UK: VSN International Ltd.

GRANDINSON, K., LUND, M. S., RYDHMER, L. and STRANDBERG, E. 2010. Genetic Parameters for the Piglet Mortality Traits Crushing, Stillbirth and Total Mortality, and their Relation to Birth Weight. Acta Agriculturae Scandinavica, Section A - AnimalScience, 52(4): 167-173.

HEINONEN, M., PELTONIEM, O. and VALROS, A. 2013. Impact of lamness and claw lesions in sows on welfare, health and Production. Livestock Science, 156(1-3): 2-9.

HELLBRÜGGE, B. 2007. Genetic aspects of piglet losses and the maternal behaviour of sows. Dissertation Thesis. Christian-Albrechts-Universität zu Kiel, Germany.

INTELICON SOFTWARE DEVELOPMENT. 2019. SPonWeb. Available at: https://www.intelicon.eu/ smallpigweb [Accessed: 2019, June 28].

JØRGENSEN, B. and ANDERSEN, S. 2000. Genetic parameters for osteochondrosis in Danish Landrace and Yorkshire boars and correlations with leg weakness and production. Animal Science, 71(3): 427-434.

KONING, D. B., DE GROOT, P. N., DE HAZELEGER, W., KEMP, B., GREVENHOF, E. M., VAN LAURENSSEN, B. F. A., DURCO, B. J. and HEUVEN, H. C. M. 2012. Associations between osteochondrosis and conformation and locomotive characteristics in pigs. Journal of Animal Science, 90: 4752-4763.

KÖCK, A., FUERST-WALTL, B., KOFLER, J., BURGSTALLER, J., STEININGER, F., FUERST, C. and EGGERDANNER, C. 2019. Short communication: Use of lameness scoring to genetically improve claw 
health in Austrian Fleckvieh, Brown Swiss, and Holstein cattle. Journal of Dairy Science, 102(2): 1397-1401.

LE, H. T., NILSSON, K., NORBERG, E. and LUNDHEIM, N. 2015. Genetic association between leg conformation in young pigs and sow reproduction. Livestock Science, 178: 9-17.

LUTHER, H., SCHWÖRER, D. and HOFER, A. 2007. Heritabilities of osteochondral lesions and genetic correlations with production and exterior traits in station-tested pigs. Animal, 1(8): 1105-1111.

PFEIFFER, C., FUERST-WALTL, B., DUCROCQ, V. and FUERST, C. 2014. Approximate multivariate genetic evaluation of functional longevity and type traits in Austrian Fleckvieh cattle. In: $10^{\text {th }}$ World Congress on Genetics Applied to Livestock Science Production. 17-22 August 2014, Vancouver, Canada. Paper No. 386.

PLUYM, L. M., VAN NUFFEL, A., VAN WEYENBERG, S. and MAES, D. 2013. Prevalence of lameness and claw lesions during different stages in the reproductive cycle of sows and the impact on reproduction traits. Animal, 7: 1174-1181.

SAS INSTITUTE. 2013. Base SAS® 9.4 Procedures Guide 2013. Statistical Procedures. $2^{\text {nd }}$ Edition. SAS Institute, Inc.: Cary, NC, USA.

SCHODL, K., REVERMANN, R., WINCKLER, C., FUERST-WALTL, B., LEEB, C., WILLAM, A., KNAPP, P. and PFEIFFER, C. 2019. Assessment of Piglet Vitality by Farmers-Validation of A Scoring Scheme and Estimation of Associated Genetic Parameters. Animals. 9(6): 317. 